\title{
An Overview on Cyclopentenyl Fatty Acids
}

\section{Hadia Almahli*}

*Department of chemistry, University of Oxford, Oxford, United Kingdom

\section{Graphical Abstract}

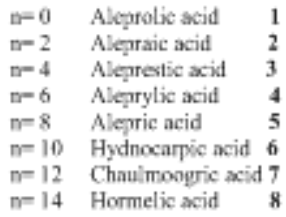

Mamaoic acid

9

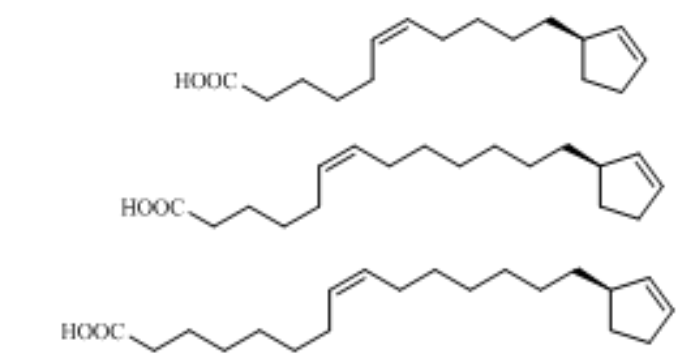

Gorlic acid

10

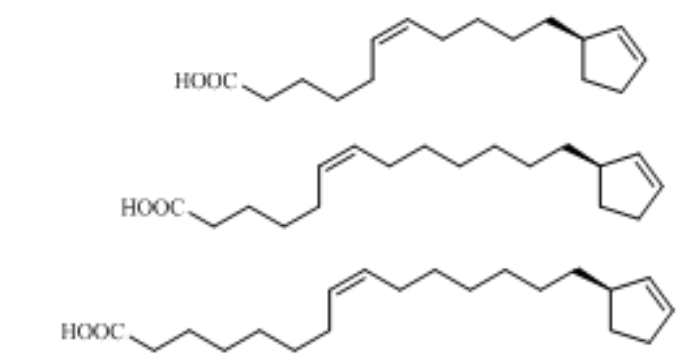

Onenbio acid

11

Abstract. This review discusses the substantial cyclopentenyl fatty acid class of naturally occurring lipids. These compounds are historically important and have recently been shown to exhibit remarkable biological activity relevant to producing new antibiotic agents. Information about the history of cyclopentenyl fatty acids, their use in traditional and modern medicine, as well as biological activity, and methods for their synthesis are given.

Keywords: Cyclopentenyl fatty acid, chaulmoogra oil, tuberculosis, leprosy, hydnocarpic acid, chaulmoogric acid.

\section{References}

Almahli H. Cyclopentenyl Fatty Acids: History, Biological Activity and Synthesis. Curr Top Med Chem. 2017 Aug 21 https://www.ncbi.nlm.nih.gov/pubmed/28828992 